\title{
The Emotional Impact of Mode of Delivery in Cameroonian Mothers: Comparing Vaginal Delivery and Caesarean Section
}

\author{
Georges Pius Kamsu Moyo ${ }^{1,}$, , Nadège Djoda ${ }^{2}$ \\ ${ }^{1}$ Faculty of Medicine and Biomedical Sciences, University of Yaoundé I, Yaoundé, Cameroon \\ ${ }^{2}$ Department of Internal Medicine, Psychiatry, Faculty of Medicine and Biomedical Sciences, University of Yaoundé I, Yaoundé, Cameroon
}

Email address:

kamsuzicfried@yahoo.fr (G. P. K. Moyo)

${ }^{*}$ Corresponding author

\section{To cite this article:}

Georges Pius Kamsu Moyo, Nadège Djoda. The Emotional Impact of Mode of Delivery in Cameroonian Mothers: Comparing Vaginal Delivery and Caesarean Section. American Journal of Psychiatry and Neuroscience. Vol. 8, No. 1, 2020, pp. 18-21.

doi: 10.11648/j.ajpn.20200801.15

Received: February 7, 2020; Accepted: February 25, 2020; Published: March 24, 2020

\begin{abstract}
Background: The rate of caesarean section delivery seems to be continuously increasing worldwide over the years. The safety of this method of delivery as far as mothers' mental state is concerned compared to vaginal delivery has been the subject of a number of studies. This study aimed at evaluating the emotional state of newly delivered women after various mode of delivery so as to enable comparison in our context. Method: A cross sectional analysis of two consecutive cohorts of newly delivered women were successively carried out from January 2014 to April 2015 at the Yaoundé Gynaeco-Obstetric and Paediatric hospital (YGOPH). The first group comprised 214 women with vaginal delivery while the second group was made of 321 women who had delivered through caesarean section. Women emotional and psychological impairments were evaluated by screening for the baby blues, which is a mild, transient and precocious depressive state of the postpartum. The Kennerley and Gath blues questionnaire which was used as the screening tool is the most approved and standardized scale for diagnosing the baby blues during the first 10 days of postpartum. Demographic information, medical, obstetrical, psychosocial and neonatal data were equally obtained. Results: The incidence of emotional instability in women with vaginal delivery was $36.9 \%$ [CI $(31.8 \%$, $42.4 \%)$ ] while that of the group of women who delivered through caesarean section was 33.3\% [CI (28.2\%, 38.8\%)]. Conclusion: Emotional instability occurred in both groups of women after vaginal delivery and caesarean section, but was less frequent after caesarean section, though not statistically significant. Therefore, psychic impairments that may occur during postpartum is bound to the delivery process as a whole and not just specific to its mode or type. However, the prevention of post-traumatic stress which may be associated with all forms of delivery, mainly by psychological support and reduction of all forms of pain should be done, regardless of the mode of delivery so as to prevent psychic complication.
\end{abstract}

Keywords: Baby Blues, Caesarean Section, Vaginal Delivery, Postpartum, Cameroon

\section{Introduction}

The susceptibility to emotional and psychological alterations in parturients and newly delivered women has for many years now been of interest for clinicians $[1,2]$. In their quest for understanding and explaining the psychogenesis of such disorders, some predisposing factors were revealed and theories advanced over the psycho-pathophysiology [2, 3]. Reviews on the topic almost agree on a possible interaction between hormonal modifications and psychosocial factors, to which could be grafted socioeconomic, neonatal or obstetrical factors [2, 3]. Obstetrical delivery can be done through two main routes, the vaginal route which is natural and caesarean section which is surgical. Vaginal delivery could be eutocic without instrumental intervention or dystocic in which case it may be made easier by episiotomy, forceps, or cupping glass $[4,5]$. A recent study showed that vaginal delivery is correlated with considerable fear of pain, which associated with other factors were responsible for $24 \%$ women having previously delivered by vaginal route, 
requesting elective caesarean section for next childbirth [6, 7]. However, it is equally possible that women choice for caesarean section change as pregnancy progresses given their susceptibility to ambivalence $[6,7]$. Some studies demonstrated the variability in women choice for elective caesarean section which is high during the first and second trimester, reduces in late pregnancy and is higher about a year after delivery [6-8]. Caesarean section may be defined as the delivery of the foetus, placenta and membranes through an incision in the abdomen and the uterine walls. It is likely to be a stressing event for women at term, rendering them psychologically vulnerable and thus could be a promoting factor for emotional imbalances as the baby blues [8-10]. On the other hand, the rate of elective caesarean section delivery has been increasing over the years especially in developed countries $[6,8,10]$. Emotional imbalances in women can lead to mood disturbances and eventually behavioural impairments [2, 3]. This study was meant to evaluate the emotional state of newly delivered women after various mode of delivery in our context.

\section{Methodology}

A cross sectional analysis of two consecutive cohorts of newly delivered women was done. The first group comprised 214 women with vaginal delivery while the second group was made of 321 women who had delivered through caesarean section. The study was conducted from January 2014 to April 2015 at the Yaoundé Gynaeco-Obstetric and Paediatric hospital (YGOPH). After approval of the protocol by the ethical committee, women who delivered at 28 weeks or more of pregnancy were enrolled, after their consent was obtained. A pretested questionnaire was administered and information retrieved from the patients' files. Data collected included socio-demographic characteristics, newborn parameters, medico-obstetrical enquiries, psychosocial information and the administration of the Kennerley and Gath blues questionnaire during the first week of postpartum. The Kennerley and Gath blues questionnaire is a validated self-rating scale consisting of 28 items concerning the emotional state of newly delivered women. The available answers are "yes" or "no" corresponding respectively to marks of 1 and 0 with a maximum score of 28 and a minimum of 0 . The scale served as a diagnostic and explorative tool. Women who had an overall score greater than the mean peak score of the sample were considered positive for emotional instability.

The recruitment of subjects was consecutive and exhaustive over a period of six months for each group. Statistical analyses were done using CSPro version 4.1 and SPSS version 22.0 software. Pearson Chi square and Fisher's exact tests were used to compare proportions. The Confidence interval (CI) was set at $95 \%$, with 0.05 precision in calculations.

\section{Results}

In the group of women who delivered by vaginal route, the mean age was $28.15 \pm 5.22$ years. The prevalence of emotional instability was $36.9 \%$ (79 women out of 214). Table 1 shows the sociodemographic characteristics of the group.

Table 1. Sociodemographic characteristics of women with vaginal delivery.

\begin{tabular}{|c|c|c|c|c|c|c|}
\hline Characteristic & Cases (79) & $\%$ & Controls (135) & $\%$ & Total (214) & $\%$ \\
\hline \multicolumn{7}{|l|}{ Cultural area } \\
\hline Sahel & 04 & 05 & 09 & 6.6 & 13 & 06 \\
\hline Forest & 20 & 25.3 & 49 & 36.2 & 69 & 32.2 \\
\hline Coast & 04 & 05 & 09 & 6.6 & 13 & 6.0 \\
\hline Grass field & 25 & 31.6 & 96 & 71.1 & 121 & 56.5 \\
\hline Foreigner & 00 & 00 & 01 & 0.7 & 01 & 0.4 \\
\hline \multicolumn{7}{|l|}{ Religion } \\
\hline Protestant & 12 & 15.1 & 35 & 25.9 & 47 & 21.9 \\
\hline Muslim & 01 & 1.2 & 08 & 5.9 & 09 & 4.2 \\
\hline Other & 08 & 10.1 & 16 & 11.8 & 24 & 11.2 \\
\hline \multicolumn{7}{|l|}{ Profession } \\
\hline House wife & 09 & 11.3 & 42 & 31.1 & 51 & 23.8 \\
\hline Civil servant & 08 & 10.1 & 25 & 18.5 & 33 & 15.4 \\
\hline Private sector & 10 & 12.6 & 19 & 14 & 29 & 13.5 \\
\hline \multicolumn{7}{|l|}{ Marital status } \\
\hline Single & 20 & 25.3 & 43 & 31.8 & 63 & 29.4 \\
\hline Married & 30 & 37.9 & 118 & 87.4 & 148 & 69.1 \\
\hline Divorced & 00 & 00 & 03 & 2.2 & 03 & 1.4 \\
\hline Widow & 00 & 00 & 00 & 00 & 00 & 00 \\
\hline Unmarried couple & 00 & 00 & 00 & 00 & 00 & 00 \\
\hline Separate & 00 & 00 & 00 & 00 & 00 & 00 \\
\hline \multicolumn{7}{|l|}{ Education level } \\
\hline Primary & 03 & 3.7 & 07 & 5.1 & 10 & 4.6 \\
\hline Secondary & 20 & 25.3 & 54 & 40 & 74 & 34.5 \\
\hline University & 27 & 34.1 & 102 & 75.5 & 129 & 60.2 \\
\hline \multicolumn{7}{|l|}{ Socioeconomic situation } \\
\hline Low & 09 & 11.3 & 42 & 31.1 & 86 & 40.1 \\
\hline
\end{tabular}




\begin{tabular}{lllllll}
\hline Characteristic & Cases (79) & \% & Controls (135) & \% & Total (214) & \% \\
\hline Average & 10 & 12.6 & 19 & 14 & 178 & 83.1 \\
High & 08 & 10.1 & 25 & 18.5 & 57 & 26.6 \\
\hline
\end{tabular}

In the group of women who delivered through caesarean section, the average age of women was $29 \pm 6$ years. The prevalence of emotional instability found was $33.3 \%$ (107 women out of 321). Table 2 shows the sociodemographic characteristics of the group.

Table 2. Sociodemographic characteristics of women with caesarean section delivery.

\begin{tabular}{|c|c|c|c|c|c|c|}
\hline Characteristic & Cases (107) & $\%$ & Controls (214) & $\%$ & Total (321) & $\%$ \\
\hline \multicolumn{7}{|l|}{ Cultural area } \\
\hline Sahel & 05 & 4.6 & 20 & 9.8 & 25 & 7.7 \\
\hline Forest & 49 & 45.7 & 91 & 42.5 & 140 & 43.6 \\
\hline Coast & 16 & 14.9 & 27 & 12.6 & 43 & 13.3 \\
\hline Grass field & 36 & 33.6 & 72 & 33.6 & 108 & 33.6 \\
\hline Foreigner & 01 & 0.9 & 04 & 1.8 & 05 & 1.5 \\
\hline \multicolumn{7}{|l|}{ Religion } \\
\hline Protestant & 35 & 32.7 & 54 & 25.2 & 89 & 27.7 \\
\hline Muslim & 07 & 6.5 & 17 & 7.9 & 24 & 7.4 \\
\hline Other & 05 & 4.6 & 15 & 7.0 & 20 & 6.2 \\
\hline \multicolumn{7}{|l|}{ Profession } \\
\hline House wife & 48 & 44.8 & 94 & 43.9 & 142 & 44.2 \\
\hline Civil servant & 19 & 17.7 & 37 & 17.2 & 56 & 17.4 \\
\hline Private section & 25 & 23.3 & 49 & 22.8 & 74 & 23 \\
\hline \multicolumn{7}{|c|}{ Matrimonial situation } \\
\hline Single & 27 & 25.2 & 38 & 17.8 & 65 & 20.2 \\
\hline Married & 49 & 45.8 & 119 & 55.6 & 168 & 52.3 \\
\hline Divorced & 01 & 0.9 & 00 & 00 & 01 & 0.3 \\
\hline Widow & 01 & 0.9 & 00 & 00 & 01 & 0.3 \\
\hline Unmarried couple & 25 & 23.4 & 50 & 23.4 & 75 & 23.3 \\
\hline Separate & 04 & 3.7 & 05 & 2.3 & 09 & 2.8 \\
\hline \multicolumn{7}{|l|}{ Education level } \\
\hline Primary & 14 & 131 & 14 & 6.5 & 28 & 8.7 \\
\hline Secondary & 57 & 53.3 & 125 & 58.4 & 182 & 56.6 \\
\hline University & 36 & 33.6 & 75 & 35.0 & 111 & 34.5 \\
\hline \multicolumn{7}{|c|}{ Socioeconomic situation } \\
\hline Low & 37 & 34.6 & 49 & 22.9 & 86 & 26.7 \\
\hline Average & 48 & 44.9 & 130 & 60.7 & 178 & 55.4 \\
\hline High & 22 & 21.2 & 35 & 16.4 & 57 & 17.7 \\
\hline
\end{tabular}

The overall number of newly delivered women recruited in the study was 538 among which 186 were diagnosed with emotional instability. The overall incidence was thus $34.6 \%$. The mean peak score on the Kennerley and Gath scale was $9 / 28$, with scores ranging from 4 to $16 / 28$.

Table 3. Most occurring symptoms among affected women.

\begin{tabular}{lll}
\hline \multirow{2}{*}{ Symptoms } & \multicolumn{2}{c}{ Cases $(\mathbf{n}=\mathbf{1 8 6})$} \\
\cline { 2 - 3 } & $\mathbf{n}$ & $\mathbf{\%}$ \\
\hline Tearful & 158 & 85.0 \\
Up and down your mood & 154 & 83.2 \\
Changeable in your spirits & 146 & 78.5 \\
Anxious & 113 & 60.7 \\
Mentally tensed & 122 & 65.4 \\
\hline
\end{tabular}

\section{Discussion}

The prevalence of emotional instability after vaginal delivery was slightly above that of caesarean section delivery in our survey, but the difference was not statistically significant. These findings are in line with other studies' results suggesting that emotional distress after delivery is not associated with the type of delivery as described by Adams et al, or better still, that there may exist no relationship between emotional state and delivery route as stipulated by Gomez Lopez et al $[9,10]$. However, the slight difference may be explained by the fact that vaginal delivery is described to be associated with considerable fear in women [5-7]. Even though the cause of this fear has not been clearly identified, strong suggestions are attributed to "pain". Nevertheless, further studies might be done to determine the factors generating the fear of vaginal delivery in women $[5,11,12]$.

It is speculated that physician explanation and counselling to patient concerning the mode of delivery could avoid alteration in women emotional state [13]. This seems to be the case with caesarean section as Gamble et al in their study found that the majority of women who requested delivery by caesarean section did so after counselling on the obstetrical or medical exigencies of their conditions [9]. However, little evidence guarantees that the increased cultural acceptance of caesarean section delivery brings about its preference among pregnant women [5-7]. This could be one of the reasons why researchers incriminate some physician-led influences on the 
continuously increasing rates of caesarean section [7].

The overall $34.6 \%$ incidence of emotional instability in newly delivered women in this survey is similar to other results obtained on the African continent. This is the case with Adewuya et al who assessed the prevalence of maternity blues in Nigerian women [14]. It therefore appears that emotional instability occurring during immediate postpartum may not be fundamentally dependent of the mode of delivery.

In this survey, women psychological evaluation was done using the Kennerley and Gath questionnaire which is the most indicated scale for assessing emotional instability of maternity blues which occurs as early as during first 10 days that follows delivery $[1,15]$. In effect maternity blues is the most precocious, benign and easy to diagnose emotional disorder of newly delivered women [1, 2, 14].

A limit of our study may be the fact that continuous evaluation of women could have revealed later manifestation of emotional disorders in which case another assessment might have been needed [16]. However, our sample size was larger than those of other researchers giving considerable power to our analyses, though equal group sizes might have accounted for more exactitude. Analysis of successive cohorts from the same setting assured consistency of diagnosis and management procedures.

\section{Conclusion}

Emotional instability occurred in both groups of women after vaginal delivery and caesarean section, but was less frequent after caesarean section though not statistically significant. Therefore, psychic impairments that may occur during postpartum is bound to the delivery process as a whole and not just specific to its mode or type. However, maternity preparation, perinatal counselling, psychological support and pain reduction in parturients may considerably reduce post-traumatic stress and possibly emotional instability or psychic disorders, regardless of the delivery route so as to prevent psychic complication.

\section{Funding}

Private.

\section{Conflict of Interest}

The authors declare that they have o competing interest.

\section{Ethical Approval}

The study was approved by the Institutional Ethics Committee.

\section{Acknowledgements}

Hospitals authorities, all collaborators to this project.

\section{References}

[1] McLeish J, Redshaw M. Mothers' accounts of the impact on emotional wellbeing of organised peer support in pregnancy and early parenthood: a qualitative study. McLeish and Redshaw BMC Pregnancy and Childbirth. 2017; 17: 28. DOI 10.1186/s12884-017-1220-0.

[2] Rezaie-Keikhaie K, Arbabshastan ME, Rafiemanesh H, Amirshahi M, Mogharabi S, Sarjou AA. Prevalence of the Maternity Blues in the Postpartum Period. J Obstet Gynecol Neoatal Nurs. 2020 https://doi.org/10.1016/j.jogn.2020.01.001.

[3] Virginie IM, Michel riex. Baby blues. Eres spirale. 2019; 89: 131-135.

[4] Pang MW et al. Impact of 1st childbirth on the changes in women's preference for mode of deliveries: follow-up of a longitudinal observational study. Birth, 2008; 35 (2): 121-8.

[5] Cheetham RW, Rzalkowoski A. Psychiatric aspects of labour and puerperium. S Afr Med J 1980; 58 (20): 814-6.

[6] Karlstrom A, Nystedt A et al. Behind the myth- few women prefer caesarean section in the absence of medical and obstetrical factors.

[7] Kingdon $\mathrm{C}$ et al. Systematic review of nulliparous women view of planned caesarean section birth: the missing component in the debate about a term cephalic trial. Birth 2006; 33 (3): 229-37.

[8] Gamble JA, Geedy DK. Women's request for a caesarean section: a critique of the literature. Birth 2000; 27 (4) 256-63.

[9] Adams SS, Eberthard-Gran M et al. Mode of delivery and postpartum emotional distress: a cohort study 55814 women. BJOG 2012; 119 (3) 298-305.

[10] Gomez Lopez et al. Delivery or caesarean section and women emotional condition. Ginecol Obstet Mex. 2008; 76 (7): 365-72.

[11] Whitburn LY, Jones LE, Davey MA, et al. The nature of labour pain: An updated review of the literature. Women Birth 2018.

[12] World Health Organization. WHO recommendations: intrapartum care for a positive childbirth experience. WHO 2018.

[13] Malalagama AS. Lack of affective communication by the staff as a risk factor for postpartum blues in an obstetric unit of a Base Hospital in Sri Lanka. SL J Psychiatry 2018; 9 (1): 15-19.

[14] Adewuya A O. Prevalence and risk factors of maternity blues in western Nigerian women. Am J Ostet Gynaecol, 2005; 193 (4): $1522-5$.

[15] Kennerley H, Gath D. Maternity blues. Br J Psychiatry. Baltimore: Williams and Wilkins, 1994; 155: 367-73.

[16] Zanardo V, Volpe F, de Luca F, Giliberti L, Giustardi A, Parotto $\mathrm{M}$ et al. Maternity blues: A risk factor for anhedonia, anxiety, and depression components of Edinburgh Postnatal Depression Scale. J Matern-Fetal Neonatal Med. 2019; 25: 1-7. 